\title{
IDEAS RePEc Rankings of Research Institutions and Economists in Viet Nam (Jan. 2022)
}

\author{
Minh-Hoang Nguyen
}

Feb. 22, 2022

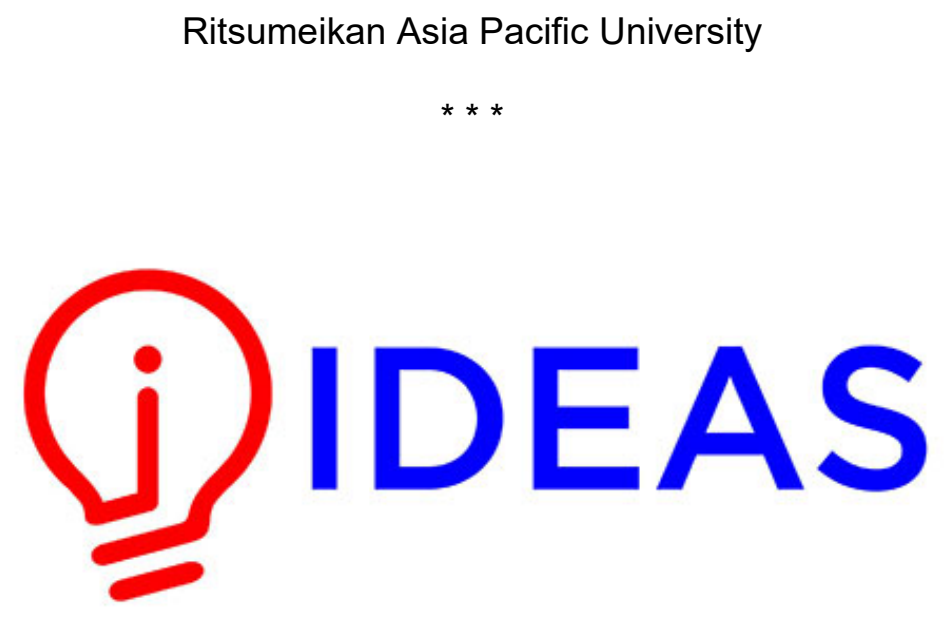

The IDEAS RePEc data tables for January 2022 shows that the top five economics research institutions in Vietnam are:

1) University of Economics Ho Chi Minh City;

2) Centre for Interdisciplinary Social Research, Phenikaa University;

3) Mekong Development Research Institute;

4) Department of Social Sciences, Economics and Management, International School, Vietnam National University; and,

5) Foreign Trade University.

The top five institutions in the list remain unchanged from the last month, except for a bit of reshuffle within the group. In this monthly ranking, the Centre for Interdisciplinary Social Research (ISR) and Mekong Development Research Institute have swapped their places over the first month of 2022.

The next pages show the full lists of the top $25 \%$ of Vietnamese institutions and authors extracted from the RePEc database as of January 2022.

IDEAS is a RePEc service hosted by the Research Division of the Federal Reserve Bank of St. Louis. RePEc uses bibliographic data supplied by the respective publishers. 


\section{(IDEAS Printed from https://ideas.repec.org/top/top.vietnam.html}

\section{Top 25\% Institutions and Economists in Viet Nam, as of January 2022}

\begin{tabular}{|c|c|c|c|c|c|}
\hline Explanations & $\underline{\text { Institutions }}$ & Institutions 10/10 & Authors & Authors 10 & More \\
\hline
\end{tabular}

\section{The rankings}

Top 25\% institutions in Viet Nam, all authors, all publication years

For Viet Nam, there are 197 authors affiliated with 59 institutions. All institutions in this region.

RankW.Rank Institution

Score Authors

Author

$\begin{array}{ll}1 & \text { [1] } \frac{\text { University of Economics Ho Chi Minh City }}{\text { Ho Chi Minh City, Viet Nam }} \\ 2 & \text { [2] } \frac{\text { Centre for Interdisciplinary Social Research, Phenikaa University }}{\text { Hanoi, Viet Nam }} \\ 3 & \text { [3] } \frac{\text { Mekong Development Research Institute }}{\text { Hanoi, Viet Nam }} \\ & \text { Department of Social Sciences, Economics and Management, International School, Vietnam }\end{array}$

$4 \quad[4]$ National University

$1.4 \quad 18$

shares

Hanoi, Viet Nam

--- [---] $\frac{\text { Institute of Business Research, University of Economics Ho Chi Minh City }}{\text { Ho Chi Minh City, Viet Nam }}$

5 [7] Foreign Trade University

6 [6] University of Economics, University of Danang

[5] Business and Economics Research Group, Ho Chi Minh City Open University

8 [9] University of Economics and Business, Vietnam National University

9 [8] School of Business and Management, RMIT University Vietnam

--- [--] School of Public Finance, University of Economics Ho Chi Minh City Ho Chi Minh City, Viet Nam

$\begin{array}{rrr}9.4 & 4 & 3 \\ 9.65 & 1 & 0.95\end{array}$

11 [11] Faculty of Economics and Public Management, Ho Chi Minh City Open University Ho Chi Minh City, Viet Nam

12 [12] Development and Policies Research Center (Depocen).

We do our best, but we cannot exclude errors.

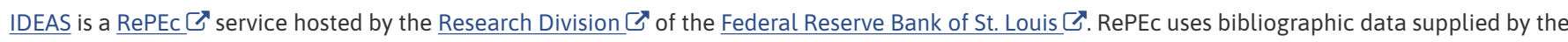
respective publishers. 
IDEAS Printed from https://ideas.repec.org/top/top.vietnam.html

\section{Top 25\% Institutions and Economists in Viet Nam, as of January 2022}

\begin{tabular}{|l|l|l|l|l|l|}
\hline Explanations & Institutions & Institutions 10/10 & Authors & Authors 10 & More \\
\hline
\end{tabular}

\section{The rankings}

Top 25\% authors in Viet Nam, all publications years

For Viet Nam, there are 197 authors affiliated with 59 institutions. All institutions in this region.

RankW.Rank Author

Score

Cuong Viet Nguyen

1 [2] Department of Social Sciences, Economics and Management, International School, Vietnam National University, Hanoi 1.45 Mekong Development Research Institute, Hanoi

2 [3] Xuan Vinh Vo

Institute of Business Research, University of Economics Ho Chi Minh City, Ho Chi Minh City 2.08

3 [5] Quan Hoang Vuong

Centre for Interdisciplinary Social Research, Phenikaa University, Hanoi $\quad 5.68$

4 [7] $\frac{\text { Thai-Ha Le }}{\text { School of Public Policy and Management, Fulbright University Vietnam, Ho Chi Minh City }}$

$5 \quad$ [14] Nguyen Phu Ha

6 [6] Duc Hong Vo

Business and Economics Research Group, Ho Chi Minh City Open University, Ho Chi Minh City

School of Public Finance, University of Economics Ho Chi Minh City, Ho Chi Minh City

[12] Thanh Dinh Su

School of Public Finance, University of Economics Ho Chi Minh City, Ho Chi Minh City

[15] Anh Ngoc Nguyen

Development and Policies Research Center (Depocen), Hanoi

[10] Tuyen Quang Tran Department of Social Sciences, Economics and Management, International School, Vietnam National University, Hanoi

[9] Toan Luu Duc Huynh University of Economics Ho Chi Minh City, Ho Chi Minh City

[25] Tung Lam Dang University of Economics, University of Danang, Danang

[23] Tung Duc Phung Mekong Development Research Institute, Hanoi

[1] Duc Khuong Nguyen

Department of Social Sciences, Economics and Management, International School, Vietnam National University, Hanoi

[24] Kien Le

Faculty of Economics and Public Management, Ho Chi Minh City Open University, Ho Chi Minh City

[29] Anh Duc Dang

Central Institution for Economic Management (CIEM), Hanoi

[18] Linh Hoang Vu

[20] Tung Manh Ho

[26] Tuan Van Nguyen

[13] Ho Manh Toan

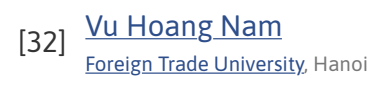


[42] Thi Thu Tra Pham

[31] Ly Dai Hung Vietnam Institute of Economics, Vietnam Academy of Social Sciences, Hanoi

[33] Quoc Trung Tran Foreign Trade University, Hanoi

[39] Binh Nguyen Thanh School of Business and Management, RMIT University Vietnam, Ho Chi Minh City

[40] Hong Kong To Nguyen Centre for Interdisciplinary Social Research, Phenikaa University, Hanoi

[21] Hoang Minh Nguyen Centre for Interdisciplinary Social Research, Phenikaa University, Hanoi

[51] Nhat Duc Nguyen

FPT School of Business (FSB), FPT University, Hanoi

[48] Tuan Huu Tran

College of Economics, Hue University, Hue City

[37] Anh The Vo

Business and Economics Research Group, Ho Chi Minh City Open University, Ho Chi Minh City

[50] Shahab Shamshirband Sr. Department of Management of Sciences and Technology Development, Ton Duc Thang University, Ho Chi Minh City

[43] Thu-Trang Vuong

Centre for Interdisciplinary Social Research, Phenikaa University, Hanoi

[56] Chuc Dinh Nguyen Institute of Regional Sustainable Development, Vietnam Academy of Social Sciences, Hanoi

[49] La Viet Phuong Centre for Interdisciplinary Social Research, Phenikaa University, Hanoi

[61] Selim Ergun

School of Business and Management, RMIT University Vietnam, Ho Chi Minh City

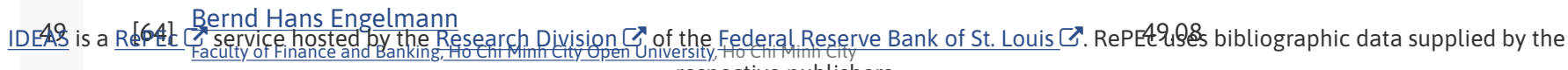
We do our best, but we cannot exclude errors. 